CASE REPORT

\title{
Right ventricular diastolic dysfunction and patent foramen ovale causing profound cyanosis
}

\author{
H Shnaider, A Shiran, A Lorber
}

Heart 2004;90:e31 (http://www.heartjnl.com/cgi/content/full/90/6/e31). doi: 10.1136/hrt.2003.026468

\begin{abstract}
A 73 year old woman presented with profound central cyanosis and a history of a minor stroke. She had normal heart morphology, normal pulmonary artery pressure, and a normal coronary angiography. A patent foramen ovale (PFO) with a massive right to left shunt was demonstrated at the atrial level, with normal pulmonary venous saturations and $\mathrm{PO}_{2}$ values. This rare, age related case of right ventricular diastolic dysfunction in a normotensive patient revealed a generous PFO allowing a pronounced right to left shunt.
\end{abstract}

A 73 year old woman presented with recent onset cyanosis and a past history of a minor stroke. Room air arterial $\mathrm{PO}_{2}$ was $40 \mathrm{~mm} \mathrm{Hg}$. Transoesophageal echocardiography revealed a patent foramen ovale (PFO) with a large right to left shunt. No other anomaly was seen.

Cardiac catheterisation disclosed normal coronary arteries and normal pulmonary pressure. Right ventricular (RV) diastolic pressure was slightly higher than left ventricular (LV) diastolic pressure. On $100 \% \mathrm{Fi} \mathrm{O}_{2}$, pulmonary venous $\mathrm{P} \mathrm{O}_{2}$ was $540 \mathrm{~mm} \mathrm{Hg}$ and the left atrial $\mathrm{P} \mathrm{O}_{2}$ was $97 \mathrm{~mm} \mathrm{Hg}$. Balloon occlusion of the PFO served to test the tolerance of PFO occlusion and to measure the effective stretched defect size. Immediate post-transcatheter PFO closure using a $24 \mathrm{~mm}$ atrial septal defect (ASD) Amplatzer occluder resulted in a rise of arterial $\mathrm{Po}_{2}$ to $320 \mathrm{~mm} \mathrm{Hg}$. Other causes of the atrial level right to left shunt such as pulmonary disease, pulmonary vascular disease, RV hypertrophy, RV systolic dysfunction, right atrial myxoma, tricuspid valve disease, and pericardial effusion were excluded.

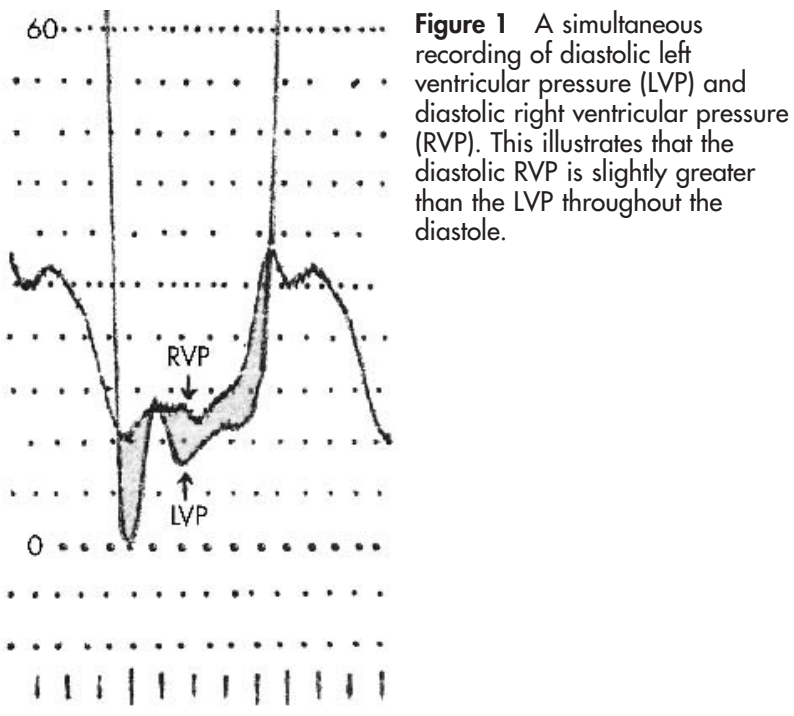

This rare, age related case of RV diastolic dysfunction in a normotensive patient revealed a generous PFO allowing a pronounced right to left shunt.

\section{DISCUSSION}

A persistent right to left shunt at the atrial level across a PFO has previously been described in relation to RV dysfunction or elevation of the pulmonary pressure in conditions such as chronic obstructive pulmonary disease, or pulmonale, recurrent pulmonary embolism, tricuspid valve dysfunction, RV infarction, and right sided myxoma. ${ }^{1}$ A significant right to left shunt via PFO has rarely been described without underlying cardiac or pulmonary disease. ${ }^{2-4}$ Several theoretical pathophysiological explanations were offered to explain such a phenomenon. Preferential streaming of the blood from the inferior vena cava across the PFO and transatrial septal pressure gradients were suggested as the likely cause for the haemodynamic state.

This is a case report of a 73 year old woman who presented with profound central cyanosis and a history of a minor stroke. She had normal heart morphology, normal pulmonary artery pressure and a normal coronary angiography. A massive right to left shunt was demonstrated at atrial level with normal pulmonary venous saturations and $\mathrm{PO}_{2}$ values. The reason for this huge right to left shunt at the PFO level is illustrated by the diastolic pressure curves representing compliance differences between right and left ventricles (fig 1). This is probably an age related phenomenon in the presence of normal LV compliance and function of this normotensive woman. Age related reduction of ventricular compliance is a frequently described finding. This is a rare case in which this age related phenomenon affected mostly the right ventricle, and in the presence of a large PFO allowed this pronounced right to left flow at the atrial level with profound cyanosis. The patient's oxygenation improved dramatically following the transient balloon occlusion of the defect. Testing the tolerance of this procedure and measuring the defect size $(22 \mathrm{~mm})$ was followed by transcatheter PFO closure by a $24 \mathrm{~mm}$ Amplatzer ASD occluder. Physical rehabilitation to normal function followed.

\section{Authors' affiliations \\ H Shnaider, A Shiran, Department of Cardiovascular Medicine, Lady Davis Medical Center, Carmel Hospital, Haifa, Israel \\ A Lorber, Pediatric Cardiology Unit, Meyer Children's Hospital, Rambam Medical Center, Haifa, Israel}

Correspondence to: Dr A Lorber, Department of Pediatric Cardiology, Meyer Children's Hospital, Rambam Medical Center, PO Box 9602, Haifa 31096, Israel; a_lorber@rambam.health.gov.il

Accepted 16 October 2003

Abbreviations: ASD, atrial septal defect; LV, left ventricular; PFO, patent foramen ovale; RV, right ventricular 


\section{REFERENCES}

1 Kerut EK, Norfleet WT, Plotnick GD, et al. Patent foramen ovale: a review of associated conditions and the impact of physiological size. J Am Coll Cardiol 2000;38:613-23.

2 Ciafone RA, Anaesty JM, Weintraub RM, et al. Cyanosis in uncomplicated atrial septal defect with normal cardiac and pulmonary arterial pressures. Chest 1998;74:596-9.
3 Thomas JD, Tabakin BS, Ittleman FP. Atrial septal defect with right to left shunt despite normal pulmonary artery pressure. J Am Coll Cardiol 1987:9:221-4

4 Godart F, Rey C, Prat A, et al. Atrial right-to-left shunting causing severe hypotemia despite normal right-sided pressure; report of 11 consecutive cases corrected by percutaneous closure. Eur Heart $J$ 2000;21:483-9. 